\title{
Positron emission tomography with
} $\left[{ }^{18} \mathrm{~F}\right]$ Fluorodeoxyglucose differentiates normal pressure hydrocephalus from Alzheimer-type
dementia

\author{
WILLIAM J JAGUST,${ }^{*} \dagger$ ROBERT P FRIEDLAND,${ }^{*} \dagger$ THOMAS F BUDINGER $\dagger$ \\ From Veterans Administration Medical Center, Martinez, the Department of Neurology, School of Medicine, \\ University of California, Davis, ${ }^{*}$ and Donner Laboratory, University of California, Berkeley, $\dagger$ California, \\ USA
}

SUMMARY Because diagnostic criteria for normal pressure hydrocephalus have not been clearly determined, it is often difficult to differentiate patients with this potentially treatable condition from those with Alzheimer-type dementia. We have studied three patients with normal pressure hydrocephalus, 17 patients with Alzheimer-type dementia, and seven healthy elderly controls using positron emission tomography and $\left[{ }^{18} \mathrm{~F}\right]$ Fluorodeoxyglucose (FDG). Both Alzheimer-type dementia and normal pressure hydrocephalus groups showed lower cortical rates of FDG utilisation than controls. However, the patterns of metabolic abnormality were distinctly different in the two dementia groups, with Alzheimer-type dementia subjects demonstrating bilateral temporoparietal hypometabolism while normal pressure hydrocephalus subjects showed globally diminished glucose use.

Normal pressure hydrocephalus is recognised as an important cause of treatable dementia,' but there is considerable confusion regarding clinical and radiographic criteria necessary to ensure a good outcome with cerebrospinal fluid shunting procedures. $^{23}$ The generally disappointing results of therapy are in large part due to the problem of separating patients with normal pressure hydrocephalus from those with the more common but untreatable Alzheimer's disease. We have found that noninvasive imaging with positron emission tomography (PET) using $\left[{ }^{18} \mathrm{~F}\right]$ Fluorodeoxyglucose (FDG) is capable of assisting in the differentiation of these two illnesses.

\section{Patients and methods}

Three male patients aged 55,58 , and 62 years met clinical criteria for the diagnosis of normal pressure hydro-

Address for reprint requests: William J Jagust, MD, Department of Neurology (127), VA Medical Center, 150 Muir Rd, Martinez, Ca, 94553, USA.

Received 29 August 1984 and in revised form 1 March 1985. Accepted 5 April 1985 cephalus. ${ }^{4}$ All experienced a gradual generalised decline in cognitive function, associated with gait difficulty and urinary incontinence. X-ray CT revealed dilated ventricles with minimal cortical atrophy, and radionuclide cisternography in all cases demonstrated ventricular reflux and delayed passage of isotope over the cerebral convexities. At the time of lumbar puncture, opening cerebrospinal fluid pressures were 120,91 , and $100 \mathrm{~mm} \mathrm{H}_{2} \mathrm{O}$ in patients 1,2 , and 3 respectively.

Patient 1 developed the syndrome 6 months after suffering a subarachnoid haemorrhage and right frontal intracerebral haematoma following rupture of a saccular aneursym of the right anterior communicating artery. Patient 2 was an alcoholic who developed a gradually progressive dementia over the course of a year with no clear precipitant. Patient 3 had experienced 3 years of difficulty with memory prior to initial evaluation and had been diagnosed as having Alzheimer's disease. Over the next six months he developed urinary incontinence and a gait disorder characterised by a wide base and magnetic stepping. An internuclear ophthalmoplegia was noted and laboratory examination showed bilaterally delayed pattern reversal visual evoked potentials and oligoclonal banding in the cerebrospinal fluid. He was presumed to have the coincidental occurrence of normal pressure hydrocephalus and multiple sclerosis. All three patients underwent lumboperitoneal shunting, and all demonstrated marked 
improvement in gait with follow-up ranging from 3 months to 2 years after operation. In addition, all underwent preand post-operative neuropsychological testing and demonstrated improvement on tests measuring sensory-motor coordination, memory, and attention (Digit-symbol substitution from the Wechsler Adult Intelligence Scale, Trail-making A and B, rapid thumb press, and memory for stories from the Wechsler Memory Scale).

Seventeen patients, eight men and nine women, aged 55 to 75 years, of varying disease severities met current research criteria for the diagnosis of Alzheimer-type dementia. $^{5}$ Scores on the Mattis dementia scale $^{6}$ were available for 16 of the patients and ranged from 55 to 129 with a mean of 93.9 (maximum 144, normal 140-144). All patients showed the gradual onset of generalised intellectual decline most marked by memory loss with the specific absence of alcoholism, hypertension, diabetes mellitus, evidence of cerebrovascular disease, previous head trauma, seizures, drug intoxication and history of psychiatric illness. All had Hachinski ischaemia scores ${ }^{7}$ of less than 4, and have undergone follow-up neurological and neuropsychological examinations every six months for 8 months to 2 years.

Seven healthy elderly subjects, two men and five women, aged 59 to 68 years, served as controls. These individuals had normal medical and neurological exams and neuropsychological tests documented an average level of functioning. Results of PET studies in Alzheimer-type dementia and control subjects in our laboratory have been presented in previous publications. ${ }^{8-11}$

PET was performed between two and six months prior to surgery and within one month of x-ray CT in all normal pressure hydrocephalus patients. Using the Donner 280crystal tomograph (resolution $8 \mathrm{~mm}$ full width at half maximum), subjects were placed in the supine position and given $\mathbf{4 5}$ minutes to acclimatise to the testing environment. During this time transmission studies using an external ${ }^{68} \mathrm{Ga}$ source were performed to facilitate attenuation correction. Subsequently $5-10 \mathrm{mCi}$ of FDG were injected intravenously followed by sampling of arterialised venous blood from a warmed hand.12 Concurrently, dynamic tomographic data were collected for 45 minutes from one transverse section. Data were collected at $5 \mathrm{~s}$ intervals for $0-120 \mathrm{~s}, 15 \mathrm{~s}$ intervals for $120-300 \mathrm{~s}, 60 \mathrm{~s}$ intervals for $300-900 \mathrm{~s}$, and $300 \mathrm{~s}$ intervals thereafter. After $45 \mathrm{~min}$, tomographic data were obtained for one to four additional levels with a scanning time of $300 \mathrm{~s}$ per section. All patients were studied in the eyes-open state in a quiet room. Sections were performed in a plane parallel to the canthomeatal line, with a slice thickness of $10 \mathrm{~mm}$.

Data were studied from the midventricular level (approximately $6 \mathrm{~cm}$ above the cathomeatal line) for all subjects by drawing regions of interest using a standard brain atlas $^{13}$ for reference to neuroanatomical structures. Regions sampled were anterior frontal, temporoparietal, and entire cortex of both hemispheres. The relatively high resolution of the system allowed for sampling of activity in small regions of cortex. Regional activity concentrations were determined (counts $/ \mathrm{cm}^{2} / \mathrm{s}$ ) for each region of interest using data obtained from 40-70 minutes after injection. Percentage differences for activity density in frontal and temporoparietal regions were calculated as the frontal- temporoparietal difference divided by the mean of the two values multiplied by 100 . These percentages provide an index of the difference between metabolic rates in frontal and temporoparietal regions, and are valid indicators of regional metabolic activity, as the concentration of ${ }^{18} \mathrm{~F} 40$ minutes after injection is related to relative regional rates of glucose use..$^{12} 14$

Regional cerebral metabolic rates of glucose ( $\left.\mathrm{rCMR}_{\mathrm{glu}}\right)$ were calculated for 10 Alzheimer-type dementia patients, seven controls, and two normal pressure hydrocephalus patients (blood input data were not available for seven Alzheimer-type dementia patients and normal pressure hydrocephalus patient 3 ). Rate constants were determined with a three-compartment model $^{15}$ using an iterative least-squares fitting method and the Marquardt algorithm. ${ }^{617}$ Values for $\mathrm{k}_{1}{ }^{*}, \mathrm{k}_{2}{ }^{*}, \mathrm{k}_{3}{ }^{*}$, and $\mathrm{k}_{4}{ }^{*}$, were derived from brain and blood time-activity curves for six control subjects and for nine of the 10 Alzheimer-type dementia subjects. Mean values of the rate constants for cortex from the Alzheimer-type dementia subjects were used with the operational equation of Phelps et al ${ }^{12}$ to determine metabolic rates in this group, while the mean values of control rate constants were used with the operational equation to determine metabolic rates for the control and normal pressure hydrocephalus subjects. For the Alzheimer-type dementia group these values were $\mathbf{k}_{1}{ }^{*}=$ $0 \cdot 123, \mathrm{k}_{2}{ }^{*}=0.225, \mathrm{k}_{3}{ }^{*}=0 \cdot 107, \mathrm{k}_{4}{ }^{*}=0.012$; while for the control group they were $\mathrm{k}_{1}{ }^{*}=0.131, \mathrm{k}_{2}{ }^{*}=0.214, \mathrm{k}_{3}{ }^{*}=$ $0.113, \mathrm{k}_{4}^{*}=0.009 \mathrm{~min}^{-1}$. Use of the operational equation minimises errors due to inaccuracies in the rate constants. ${ }^{12}$ Although the value for the lumped constant has not been $\stackrel{9}{\circ}$ 음 studied in diseased human brain, we used the value of $0.52 \stackrel{\mathbb{D}}{\Omega}$ as recently measured by Reivich and coworkers in nine $\bar{Z} Z$ normal young males. ${ }^{18}$ The metabolic rates reported here can be compared to the work of other laboratories by multiplying by the ratio of lumped constants.

\section{Results}

PET images at the mid-ventricular level for each normal pressure hydrocephalus patient are presented in fig 1 , along with representative images from an Alzheimer patient and control subject. The obvious temporoparietal hypometabolism observed in the Alzheimer-type dementia patient is not seen in the images from normal pressure hydrocephalus patients. This temporoparietal hypometabolism was found in all Alzheimer-type dementia patients regardless of disease severity, age, or sex. The image for patient 1 shows diminished activity in the right frontal region resulting from the haematoma and resultant infarction. All other normal pressure hydrocephalus patients show an even distribution of cortical activity.

Figure 2 presents data for frontal-temporoparietal percentage differences for each hemisphere in each group. Values from normal pressure hydrocephalus patient 1 are excluded in the analysis of the right hemisphere data since the right frontal lesion produced markedly lowered activity counts in 

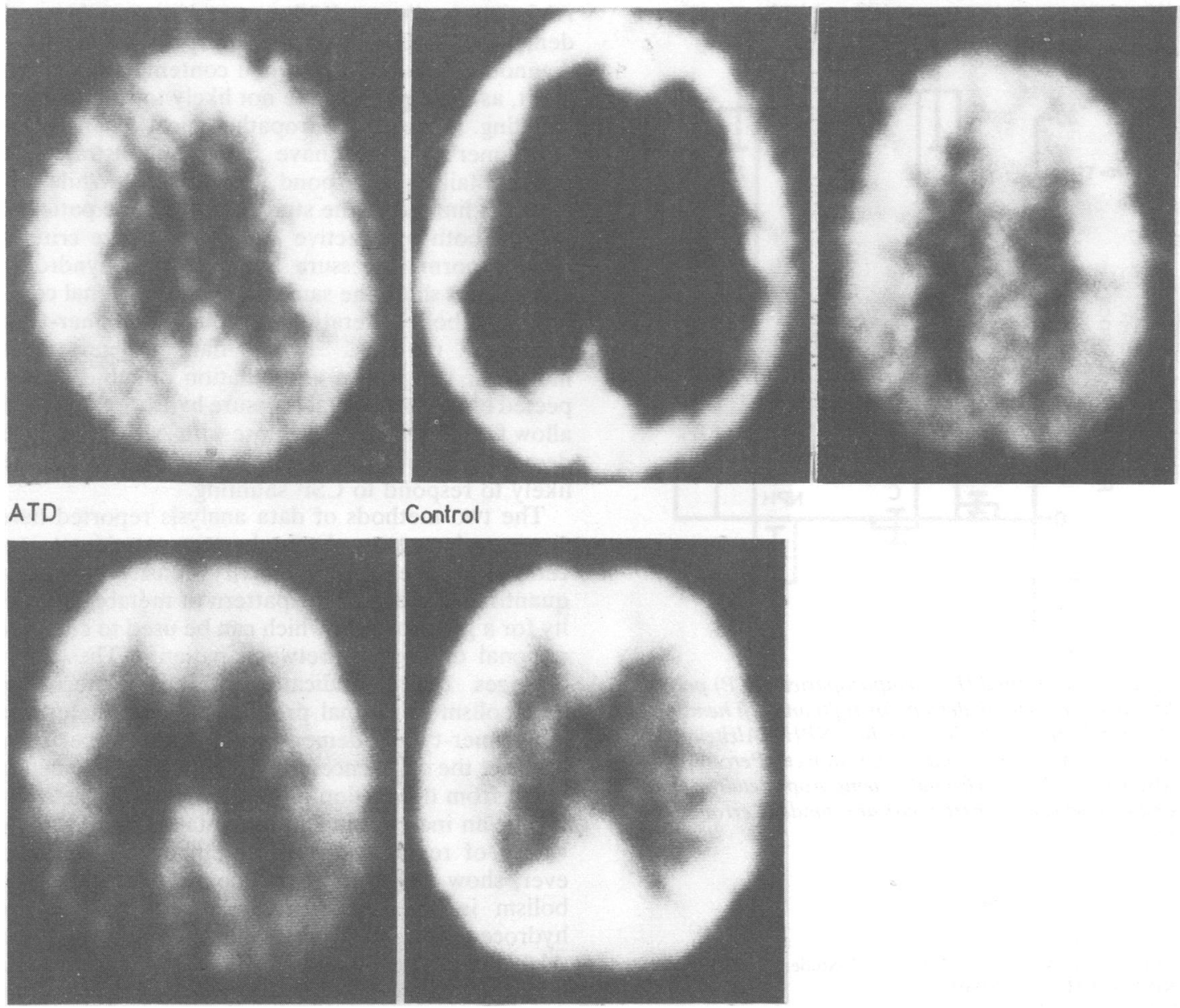

Fig 1 PET images obtained at the mid-ventricular level for normal pressure hydrocephalus patients (patients 1, 2, and 3), and representative images from an Alzheimer-type dementia and control subject.

the right frontal lobe which are not reflective of the pathology of normal pressure hydrocephalus. The values are significantly different for the normal pressure hydrocephalus and Alzheimer-type dementia groups, although control and normal pressure hydrocephalus groups are different only for left hemisphere values. Alzheimer-type dementia subjects are also significantly different from the control subjects.

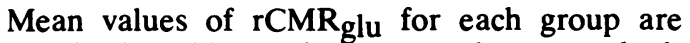
shown in the table. Both the normal pressure hydrocephalus and Alzheimer subjects have lower metabolic rates than controls. The Alzheimer-type dementia patients show hypometabolism relative to control subjects which is most marked in tem- poroparietal cortex, while the disturbed metabolism in normal pressure hydrocephalus is evenly distributed.

\section{Discussion}

The diagnosis of normal pressure hydrocephalus is only certain retrospectively by demonstrating improvement following CSF shunting. Research has thus been concerned with delineating clinical and laboratory criteria which predict a good response to shunting. Nevertheless, overall success rates have been disappointing, ranging from 24 to $60 \%$ in clinical series. ${ }^{19}$

Exclusion of patients unlikely to respond to CSF 


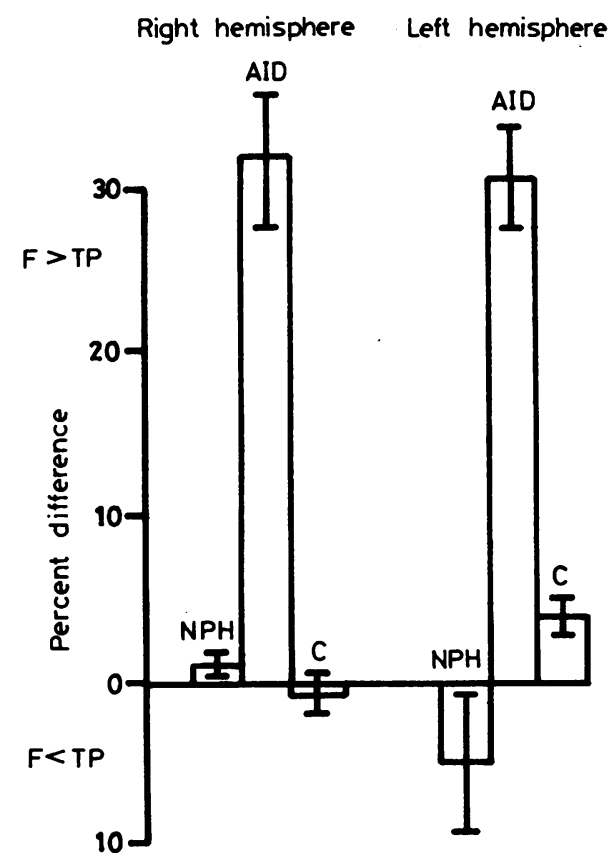

Fig 2 Mean frontal (F)-temporoparietal (TP) percent differences in activity density for right and left hemispheres of normal pressure hydrocephalus (NPH), Alzheimer-type dementia (ATD) and control (C) subjects. Percent difference $=100 \times($ frontal - temporoparietal $/$ frontal + temporoparietal/2). Error bars are standard error of the mean.

For Right Hemisphere

$\mathrm{NPH} N=2$, ATD $N=17, \mathrm{C} \mathrm{N}=7$, Student's t test, two tailed NPH vs ATD $-p<0.05$

NPH vs C - NS

ATD vs $C-p<0.001$

For Left Hemisphere

NPH N $=3$, ATD $N=17, C N=7$, Student's t test, two tailed NPH vs ATD $-p<0.001$

NPH vs $C-p<0.05$

ATD vs $C-p<0.001$ shunting would contribute to higher success rates. Alzheimer's disease is the most common form of dementia ${ }^{23}$ and as such represents an important diagnostic consideration when contemplating treatment, as these patients are not likely to benefit from shunting. Indeed, neuropathological changes of Alzheimer's disease have been demonstrated in patients failing to respond to shunts. ${ }^{24}{ }^{25}$ While our report is limited to the study of only three patients, they fit both prospective and retrospective criteria for the normal pressure hydrocephalus syndrome and did not share the same pattern of regional cerebral metabolic alterations as our Alzheimer-type dementia patients. These data suggest that metabolic imaging in a population of subjects suspected of having normal pressure hydrocephalus will allow for identification of those with Alzheimer-type dementia, providing a residual population more likely to respond to CSF shunting.

The two methods of data analysis reported here are complementary. Frontal-temporoparietal percentage differences for activity density provide a quantitative index of the pattern of metabolic activity for a given patient which can be used to compare regional differences between patients. These percentages clearly indicate different patterns of metabolism in normal pressure hydrocephalus and Alzheimer-type dementia, without specifying whether the differences in Alzheimer-type dementia result from depression of temporoparietal metabolism or an increase in frontal metabolism. Absolute values of regional cerebral metabolic rates, however, show a definite depression of cerebral metabolism in all brain regions in normal pressure hydrocephalus, and in temporoparietal cortex in Alzheimer-type dementia. Taken together, these findings indicate that both the dementias of normal pressure hydrocephalus and Alzheimer-type disease are characterised by hypometabolism, while the regional distribution of these metabolic abnormalities is distinctly different.

Our findings in Alzheimer-type dementia are in agreement with other studies of cerebral metabolism which have also found a focal or multifocal nature of

Table Means and standard deviations (SD) of regional glucose utilisation rates in cortex (mg glucose/100 cc/min) for normal pressure hydrocephalus, Alzheimer-type dementia, and control groups

\begin{tabular}{|c|c|c|c|c|c|c|}
\hline Patients & $R F$ & $L F$ & $R T P$ & $L T P$ & $R$ Ent & L Ent \\
\hline $\begin{array}{l}\mathrm{NPH} \\
(\mathrm{N}=2) \\
\mathrm{ATD} \\
(\mathrm{N}=10) \\
\text { Control } \\
(\mathrm{N}=7)\end{array}$ & $\begin{array}{c}3 \cdot 81 \\
(2.25) \\
6.27 \\
(1.40) \\
7.23 \\
(0.94)\end{array}$ & $\begin{array}{c}4.46 \\
(1.12) \\
5.81 \\
(1.46) \\
6.88 \\
(0.88)\end{array}$ & $\begin{array}{c}4 \cdot 37 \\
(1 \cdot 38) \\
4 \cdot 54 \\
(1 \cdot 21) \\
7 \cdot 37 \\
(1.02)\end{array}$ & $\begin{array}{c}4.58 \\
(0.67) \\
4.31 \\
(1.19) \\
6.85 \\
(0.96)\end{array}$ & $\begin{array}{c}4.35 \\
(1.71) \\
5 \cdot 83 \\
(1.23) \\
7.37 \\
(0.94)\end{array}$ & $\begin{array}{c}4.71 \\
(1.10) \\
5.46 \\
(1.42) \\
6.94 \\
(0.96)\end{array}$ \\
\hline
\end{tabular}

RF-right frontal cortex, LF-left frontal cortex, RTP—right temporoparietal cortex, LTP-left temporoparietal cortex, R Ent-right entire cortex, L Ent-left entire cortex. 
the abnormality, with hypometabolism most marked in temporoparietal and frontal association cortex and less involvement of motor, somatosensory and primary visual cortex. ${ }^{26-28}$ The global hypometabolism which we found in normal pressure hydrocephalus, however, contradicts the prevailing theories about the pathophysiology of the illness. It has been suggested that symptoms are caused by primary involvement of the frontal lobes, with stretching of leg fibres in the corona radiata ${ }^{29}$ or selective ischaemia in the distribution of the anterior cerebral artery. ${ }^{30}$ Our findings of equal involvement of all cortical regions argues against selective involvement of any one cortical area. However, limitations in spatial resolution limits the quantitation of metabolism in white matter. Focal alterations in periventricular white matter caused by transudation of CSF or intermittently increased pressure would not be detected with this procedure. An earlier study by Grubb et $a^{31}$ evaluated cerebral blood flow and metabolism (by measuring the cerebral metabolic rate of oxygen) in normal pressure hydrocephalus and dementia with cortical atrophy. While these investigators noted diminished flow and metabolism in both groups, neither the regional patterns of flow and metabolism nor the changes in these parameters following removal of CSF differentiated the two groups. These findings might be explained by the poorer resolution of their nontomographic technique, and because the cortical atrophy group contained patients with several different types of dementia.

The images and the quantitative data presented here are not diagnostic of the normal pressure hydrocephalus syndrome. Nevertheless, it is clear that when confronted with the demented patient who appears to be a candidate for shunting, PET may allow for exclusion of a subgroup with Alzheimertype dementia and therefore increase the likelihood of a favourable outcome. While the present prohibitive expense and technological support needed for PET studies preclude its use by the general medical community, recent developments in single photon emission computed tomography with new radiopharmaceuticals to measure blood flow allow more practical methods of evaluating cerebral physiology in vivo. ${ }^{32-34}$ Although flow and metabolism appear to be normally coupled in Alzheimertype dementia, ${ }^{28}$ further studies are needed to evaluate this issue in normal pressure hydrocephalus patients. Evaluation of a larger number of well defined patients are required in order to demonstrate that single photon emission computed tomography studies of cerebral flow will yield equivalent information to that obtained with these PET metabolic studies. Our results suggest that the gen- eral availability of such a technique will be of value in the differential diagnosis of dementia.

We express our thanks to Dr J St John for referral and surgical treatment of the patients, to Drs E Koss and BA Ober for neuropsychological testing and statistical advice, to Dr R Huesman and B Knittel for technical assistance, and to Dr P Weinstein for reviewing the manuscript. This work was supported by the Medical Research Service of the United States Veterans Administration and by the Director, Office of Energy Research, Office of Health and Environmental Research of the United States Department of Energy under contract No. DEAC03-76SF00098.

\section{References}

' Fisher CM. The clinical picture in occult hydrocephalus. Clin Neurosurg 1977;24:270-84.

${ }^{2}$ Messert B, Wannamaker BB. Reappraisal of the adult hydrocephalus syndrome. Neurology (Minneap) 1974; 24: 1224-31.

${ }^{3}$ Huckman MS. Normal pressure hydrocephalus: evaluation of diagnostic and prognostic tests. AJNR 1981;2:385-95.

${ }^{4}$ Ojemann RG. Normal pressure hydrocephalus. Clin Neurosurg 1972;18:337-70.

${ }^{5}$ Eisdorfer C, Cohen D. Diagnostic criteria for primary neuronal degeneration of the Alzheimer type. J Fam Pract 1980; 11:553-7.

- Mattis S. Mental status examination for organic mental syndrome in the elderly patient. In: Bellak L, Katsu T, eds. Geriatric psychiatry: a handbook for psychiatrists and primary care physicians, vol 7. New York: Grune and Stratton, 1976:77-121.

${ }^{7}$ Hachinski VC, Iliff LD, Phil M, et al. Cerebral blood flow in dementia. Arch Neurol 1975;32:632-7.

${ }^{8}$ Friedland RP, Budinger TF, Ganz E, et al. Regional cerebral metabolic alterations in dementia of the Alzheimer type: positron emission tomography with $\left[{ }^{18} \mathrm{~F}\right]$ fluorodeoxyglucose. J Comput Assist Tomogr 1983; 7:590-8.

${ }^{9}$ Friedland RP, Budinger TF, Brant-Zawadzki M, Jagust WJ. The diagnosis of Alzheimer-type dementia: a preliminary comparison of positron emission tomography and proton magnetic resonance. JAMA 1984; 252: $2750-2$.

${ }^{10}$ Friedland RP, Budinger TF, Koss E, Ober BA. Alzheimer's disease: anterior-posterior and lateral hemispheric alterations in cortical glucose utilization. Neurosci Lett 1985;53:235-40.

"Koss E, Friedland RP, Ober BA, Jagust WJ. Lateral hemispheric asymmetries of glucose utilization are different in early and late onset Alzheimer-type dementia. Am J Psychiatry 1985; 142:638-40.

12 Phelps ME, Huang SC, Hoffman EJ, Selin C, Sokoloff L, Kuhl DE. Tomographic measurement of local cerebral glucose metabolic rate in humans with (F-18) 
2-fluoro-2-deoxy-d-glucose: validation of method. Ann Neurol 1979;6:371-88.

${ }^{13}$ Matsui T, Hirano A. An atlas of the human brain for computerized tomography. Tokyo: Igaku-Shoin, 1978.

${ }^{14}$ Reivich M, Kuhl DE, Wolf A, et al. The $\left[{ }^{18} \mathrm{~F}\right]$ fluorodeoxyglucose method for the measurement of local cerebral glucose utilization in man. Circ Res 1979;44:127-37.

${ }^{15}$ Sokoloff L, Reivich M, Kennedy C, et al. The $\left[{ }^{14} \mathrm{C}\right] \mathrm{de}-$ oxyglucose method for the measurement of local cerebral glucose ulilization: theory, procedure, and normal values in the conscious and anesthetized albino rat. J Neurochem 1977;28:897-916.

${ }^{16} \mathrm{Knittel}$ B. Kinetic analysis of dynamic PET data. Master's thesis, University of California, Berkeley, 1983. Lawrence Berkeley Laboratory report 17313.

${ }^{17}$ Marquardt DW. An algorithm for least-squares estimation of nonlinear parameters. J Soc Indust Appl Math 1963;11:431-41.

${ }^{18}$ Reivich M, Alavi A, Wolf A, et al. Glucose metabolic rate kinetic model parameter determination in humans: the lumped constant and rate constants for $\left[{ }^{18} \mathrm{~F}\right]$ fluorodeoxyglucose and $\left[{ }^{11} \mathrm{C}\right]$ deoxyglucose. $J$ Cereb Blood Flow Metabol 1985;5:179-92.

${ }^{19}$ Black PM. Idiopathic normal pressure hydrocephalus. Results of shunting in 62 - patients. $J$ Neurosurg 1980;52:371-7.

${ }^{20}$ Laws ER, Mokri B. Occult hydrocephalus: results of shunting correlated with diagnostic tests. Clin Neurosurg 1977;24:316-33.

${ }^{21}$ Stein SC, Langfitt TW. Normal pressure hydrocephalus: predicting the results of cerebrospinal fluid shunting. $J$ Neurosurg 1974;41:463-70.

${ }^{22}$ Greenberg JO, Shenkin HA, Adam R. Idiopathic normal pressure hydrocephalus - a report of 73 patients. J Neurol Neurosurg Psychiatry 1977;40:336-41.

${ }^{23}$ Katzman $R$. The prevalence and malignancy of Alzheimer's disease. Arch Neurol 1976;33:217-9.
${ }^{24}$ Ball MJ. Neurofibrillary tangles in the dementia of "normal pressure" hydrocephalus. Can J Neurol Sci 1976;3:227-35.

${ }^{25}$ Coblentz JM, Mattis S, Zingesser LH, Kasoff SS, Wisniewski HM, Katzman R. Presenile dementia. Clinical aspects and evaluation of cerebrospinal fluid dynamics. Arch Neurol 1973;29:299-308.

${ }^{26}$ Benson DF, Kuhl DE, Hawkins RA, Phelps ME, Cummings JL, Tsai SY. The fluorodeoxyglucose ${ }^{18} \mathrm{~F}$ scan in Alzheimer's disease and multi-infarct dementia. Arch Neurol 1983;40:711-4.

${ }^{27}$ Cutler NR, Duara R, Grady CL, Haxby JL, Kessler R, Rapoport SI. Brain metabolism and neuropsychology in Alzheimer's dementia. Neurology (NY) 1984; 34(suppl 1): 101 .

${ }^{28}$ Frackowiak RSJ, Pozzilli C, Legg NJ, et al. Regional cerebral oxygen supply and utilization in dementia. Brain 1981;104:753-78.

${ }^{29}$ Fisher CM. Hydrocephalus as a cause of disturbances of gait in the elderly. Neurology (NY) 1982;32:1358-63.

${ }^{30}$ Mathew NT, Meyer JS, Hartmann A, Ott EO. Abnormal cerebrospinal fluid-blood flow dynamics. Implications in diagnosis, treatment, and prognosis in normal pressure hydrocephalus. Arch Neurol 1975;32:65764.

${ }^{31}$ Grubb RL, Raichle ME, Gado MH, Eichling JO, Hughes CP. Cerebral blood flow, oxygen utilization, and blood volume in dementia. Neurology (Minneap) 1977;27:905-10.

${ }^{32}$ Kuhl DE, Barrio JR, Huang SC, et al. Quantifying $\mathbb{D}$ local cerebral blood flow by $N-\frac{\rho}{\Phi} \frac{0}{J}$ isopropyl-p-[ ${ }^{123}$ I] iodoamphetamine (IMP) tomography. J Nucl Med 1982;23:196-203.

${ }^{33}$ Holman BL, Hill TL, Magistretti PL. Brain imaging with emission computed tomography and radiolabeled amines. Invest Radiol 1982;17:206-15.

${ }^{34}$ Ackerman RH. Of cerebral blood flow, stroke, and SPECT. Stroke 1984;15:1-4. 